\title{
Influência antrópica em três ecótonos floresta/campo da Floresta Atlântica do Sudeste do Brasil: análise de micropartículas carbonizadas em solos superficiais
}

\author{
Paulo Eduardo De Oliveiraa ${ }^{1,3}$ e Maria da Glória Silva Bispo Passacantili ${ }^{2}$
}

Recebido: 13.05.2010; aceito: 08.12.2010

\begin{abstract}
Anthropogenic influence on forest/savanna ecotones of the Atlantic Forest of Southeastern Brazil: soil charred particles analysis). Charred microscopic particles found in superficial soils were quantified to determine the intensity of fires in three areas of the Atlantic Rainforest of southeastern Brazil. Charred particles were separated into three main size categories: $<25 \mu \mathrm{m}, 26$ to $50 \mu \mathrm{m}$ and $>51 \mu \mathrm{m}$. The data suggest that all areas were subjected to fires in recent times. The savannas of Linhares were the most affected by fires in an order of magnitude up to 10 times that observed in São Paulo, however the Linhares forests showed a low level of fire impact. On the other hand, the two forest localities of São Paulo showed high frequency of fires. These results suggest that fire can be a determining factor in the physiognomy of the vegetation. However, there is no evidence that the presence of forest/savanna mosaics can be explained only by the incidence of anthropogenic fires.
\end{abstract}

Key words: Atlantic rainforest, charred particles, Lycopodium, paleofires

RESUMO - (Influência antrópica em três ecótonos floresta/campo da Floresta Atlântica do Sudeste do Brasil: análise de micropartículas carbonizadas em solos superficiais). Através da quantificação de micropartículas carbonizadas em solos superficiais, determinou-se a intensidade de incêndios recentes em três áreas da Floresta Atlântica com mosaico floresta/ campo: duas na Serra do Mar, São Paulo e uma na Reserva Natural Vale do Rio Doce, Linhares, Espírito Santo. As micropartículas foram quantificadas em três classes de tamanho: $<25 \mu \mathrm{m}$, de 26 a $50 \mu \mathrm{m}$ e $>51 \mu \mathrm{m}$. Os dados mostram que as três áreas estiveram recentemente sujeitas a incêndios. Os campos da Reserva de Linhares foram os mais afetados, numa ordem de magnitude até 10 vezes maior do que na Serra do Mar, embora suas florestas tenham apresentado um baixo padrão de impacto. Os resultados sugerem que o fogo pode ser um fator determinante da fisionomia da vegetação, contudo não há evidência de que o mosaico floresta/campo possa ser explicado somente pela incidência de impactos antrópicos, na forma de incêndios.

Palavras-chave: campo, carvão, Floresta Atlântica, Lycopodium, paleoincêndios

\section{Introdução}

Um dos aspectos mais intrigantes da fisionomia da Floresta Atlântica é a presença de grandes áreas em que ocorre o ecótono floresta/campo, apesar de o clima reinante favorecer a ocorrência exclusivamente de floresta. Na literatura botânica brasileira duas hipóteses foram propostas para elucidar esse problema, que ocorre também em outros ecossistemas brasileiros: origem natural dos campos e origem antrópica. A hipótese da origem antrópica dos campos permeou a literatura científica brasileira a partir do século XX
(Warming 1908) e essa polêmica se desenvolveu principalmente nos trabalhos de Rawitscher (1944), Christofoletti (1966), Ab'Saber (1971), Goodland (1979) e Eiten (1994). Para Warming (1908) o fator primordial para o estabelecimento dos campos é o clima, enquanto Eiten (1994) explica a origem dos campos em áreas florestais como resultado de condições edáficas. Por outro lado, Rawitscher (1944) advoga o fogo como o fator primordial na formação da fisionomia campestre em áreas de clima úmido.

Segundo Pillar (2003), que advoga a hipótese antrópica, o emprego do fogo e o uso da terra para

1. Universidade de São Paulo, Instituto de Geociências, Departamento de Geologia Sedimentar e Ambiental, Rua do Lago 562, Cidade Universitária, 05508-080 São Paulo, SP, Brasil

2. Mestrado em Análise Geoambiental, Universidade Guarulhos

3. Autor para correspondência: paulo@bjd.com.br 
pasto, provavelmente, são os principais fatores para a ocorrência ou pelo menos para a manuteção do ecótono floresta/campo no domínio da Mata Atlântica.

Através de um estudo paleoecológico, embasado em análises de isótopos de carbono, Mofatto (2005) e Pessenda et al. (2009) mostraram que os campos de altitude presentes atualmente no Núcleo Curucutu, Parque Estadual Serra do Mar, em São Paulo, têm uma origem climática uma vez que eles estavam estabelecidos antes do UMG (Último Máximo Glacial), ou seja, entre 22.000 e 14.000 anos Antes do Presente (A.P.). Não obstante essas dissensões, um fator pouco analisado em relação à problemática da origem das ilhas de savana, dentro de domínios florestais, é a intensidade e frequência de paleoincêndios como determinantes na fisionomia vegetal contemporânea. Uma forma de avaliar o impacto de paleoincêndios, tanto os recentes quanto os que ocorreram há milhares de anos, é a análise de partículas carbonizadas, que, por serem inertes, se preservam em solos, sedimentos lacustres, turfeiras e em outros locais que favorecem a sua sedimentação.

O objetivo principal deste trabalho é quantificar a ocorrência de incêndios recentes em três áreas de proteção ambiental da Floresta Atlântica do Sudeste do Brasil, caracterizadas pela presença de mosaico floresta/campo. Entre os objetivos secundários encontra-se o levantamento da influência antrópica na possível expansão da vegetação campestre em dois locais na Serra do Mar e compará-lo com uma área floresta/campo na Reserva Natural da Companhia Vale do Rio Doce, Linhares, Espírito Santo. Embora se saiba, hoje, que esses campos, em associação com a Floresta Atlântica, estavam estabelecidos na área do atual Parque Estadual da Serra do Mar desde o final do Pleistoceno, este estudo contribuirá com o entendimento do processo de sucessão vegetal em áreas de écotonos.

Características ambientais das áreas de estudo - Duas áreas situadas no setor sul da Serra do Mar, no Estado de São Paulo, foram selecionadas para o estudo. A primeira está localizada no Núcleo Curucutu, do Parque Estadual Serra do Mar, no extremo sul do Município de São Paulo, SP, Brasil. Esta área possuía 12.090 hectares que foram transformados em reserva florestal pelo governo do Estado de São Paulo em 1958, e posteriormente anexados ao Parque, hoje com área total de 25.409 ha (Garcia 2003). A sede do Núcleo Curucutu (2359'06"S e 4644'36”W) e sua área está situada em altitudes entre 750 e 900 m
(Garcia 2003). Segundo Nogueira (2002) a vegetação é constituída de um mosaico de floresta e campos de altitude, frequentemente cobertos por neblina. Embora as condições climáticas sejam favoráveis à vegetação florestal, os solos pobres e ácidos com concreções lateríticas e propícios à erosão contribuem para a manutenção dos campos na região.

O clima predominante é o temperado chuvoso (Cfa) do sistema Köppen de classificação, devido à influência das massas de ar. Os verões são quentes e chuvosos e os invernos têm temperaturas mais brandas. Os meses mais chuvosos ocorrem entre dezembro e março e os menos chuvosos de maio a agosto. A amplitude pluviométrica oscila entre 3.000 e $4.000 \mathrm{~mm}$ anuais (Sant'Anna Neto 1990).

A segunda área, localizada ao longo da antiga Estrada de Ferro Sorocabana, está fora do limite do Parque Estadual Serra do Mar, mas está dentro do mesmo contexto climático e vegetacional. A localização das duas áreas estudadas na região da Serra do Mar, no Estado de São Paulo, é mostrada na figura 1.

A terceira área estudada está inserida na Reserva Natural da Companhia do Vale do Rio Doce S.A. (RNVRD) está localizada nos municípios de Linhares e Jaguaré (ES), em altitudes entre 28 a 65 m, numa área de 22.000 ha localizada entre as coordenadas $19^{\circ} 06^{\prime} \mathrm{S}$ a $19^{\circ} 18^{\prime} \mathrm{S}$ a $39^{\circ} 45^{\prime} \mathrm{W}$ a $40^{\circ} 19^{\prime} \mathrm{W}$, como mostra a figura 2. A vegetação predominante é conhecida como Floresta Atlântica de Tabuleiros Terciários e difere da Floresta Atlântica da Serra do Mar do Estado de São Paulo, pela presença de topografia plana, com clima sempre quente, composta de solos mais pobres e presença de poucas epífitas (Rizzini et al. 1997).

Outra característica determinante na diferenciação desse tipo de Mata Atlântica da encontrada no Estado de São Paulo é a presença significativa de vários táxons arbóreos amazônicos (Radambrasil 1983). Na RNVRD várias ilhas de savana são localmente denominadas campos nativos. O clima é do tipo AW de Köppen, caracterizado pela acentuada sazonalidade, com uma estação chuvosa no verão e seca ou úmida no inverno com temperatura média em meses menos quentes, acima de $18{ }^{\circ} \mathrm{C}$. O período mais chuvoso está restrito aos meses de outubro a março, enquanto que o período mais seco estende-se de abril a setembro, com precipitação inferior a $25 \%$ do total anual. A precipitação anual total oscila ao redor de 1.200 $\mathrm{mm}$ /ano. A temperatura média anual é de $24,6^{\circ} \mathrm{C}$, variável entre $22^{\circ} \mathrm{C}$ e $27^{\circ} \mathrm{C}$ (Garay \& Rizzini 2004). 

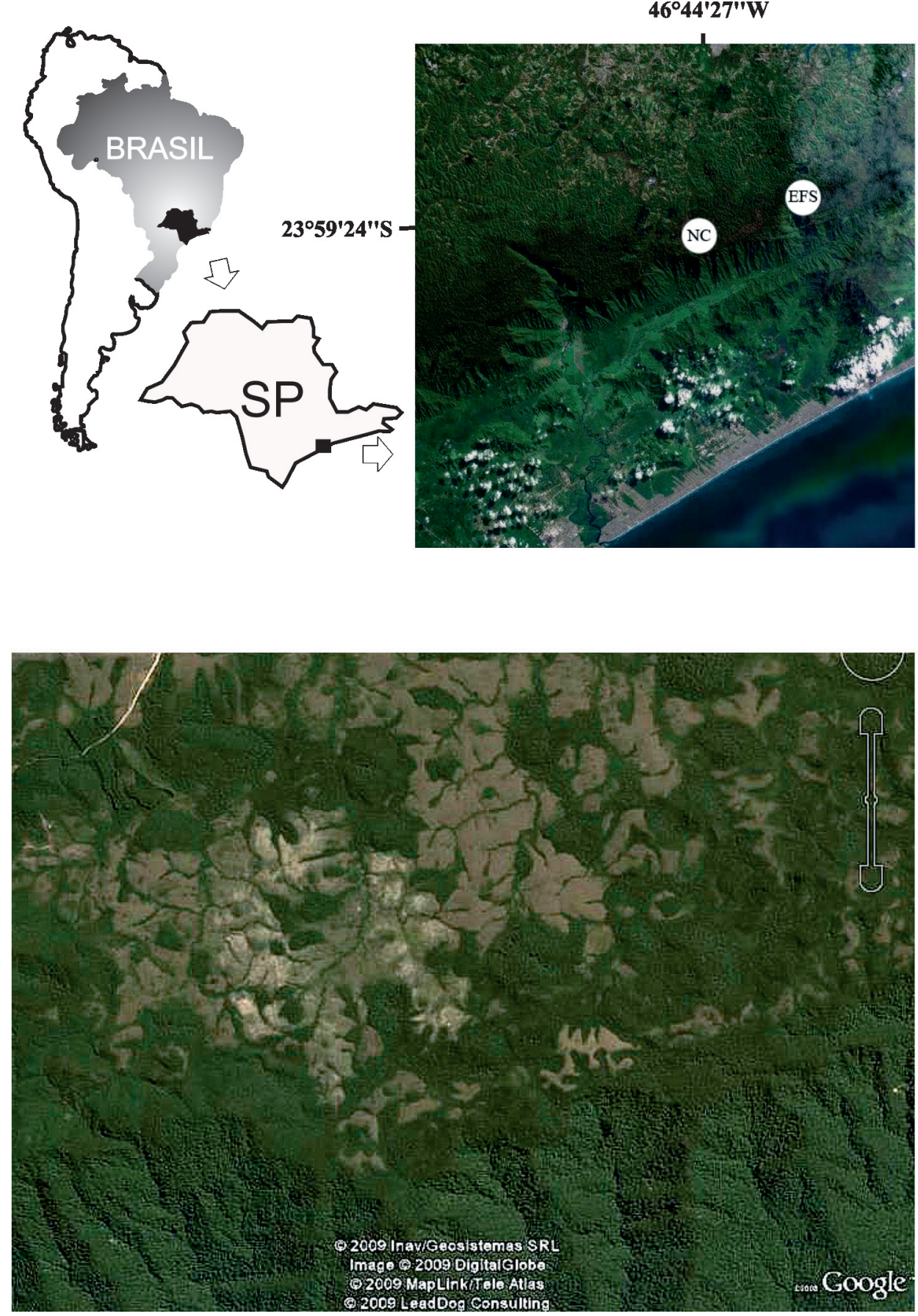

Figura 1. Localização do Núcleo Curucutu, Parque Estadual da Serra do Mar, representado pela sigla NC e a área amostrada nas proximidades da Estrada de Ferro Sorocaba, representada pela sigla EFS. A foto inferior mostra a área de ocorrência do ecótono campo/ floresta dentro do Parque Estadual da Serra do Mar (imagens obtidas de www.googlearth.com).

Figure 1. Location of the Curucutu Nucleus, Serra do Mar State Park, represented by NC, and the sampled area within the proximity of the Sorocabana Railway, represented by EFS. The lower satellite image shows the savanna/forest ecotone within the Serra do Mar State Park (images obtained from www.googlearth.com). 


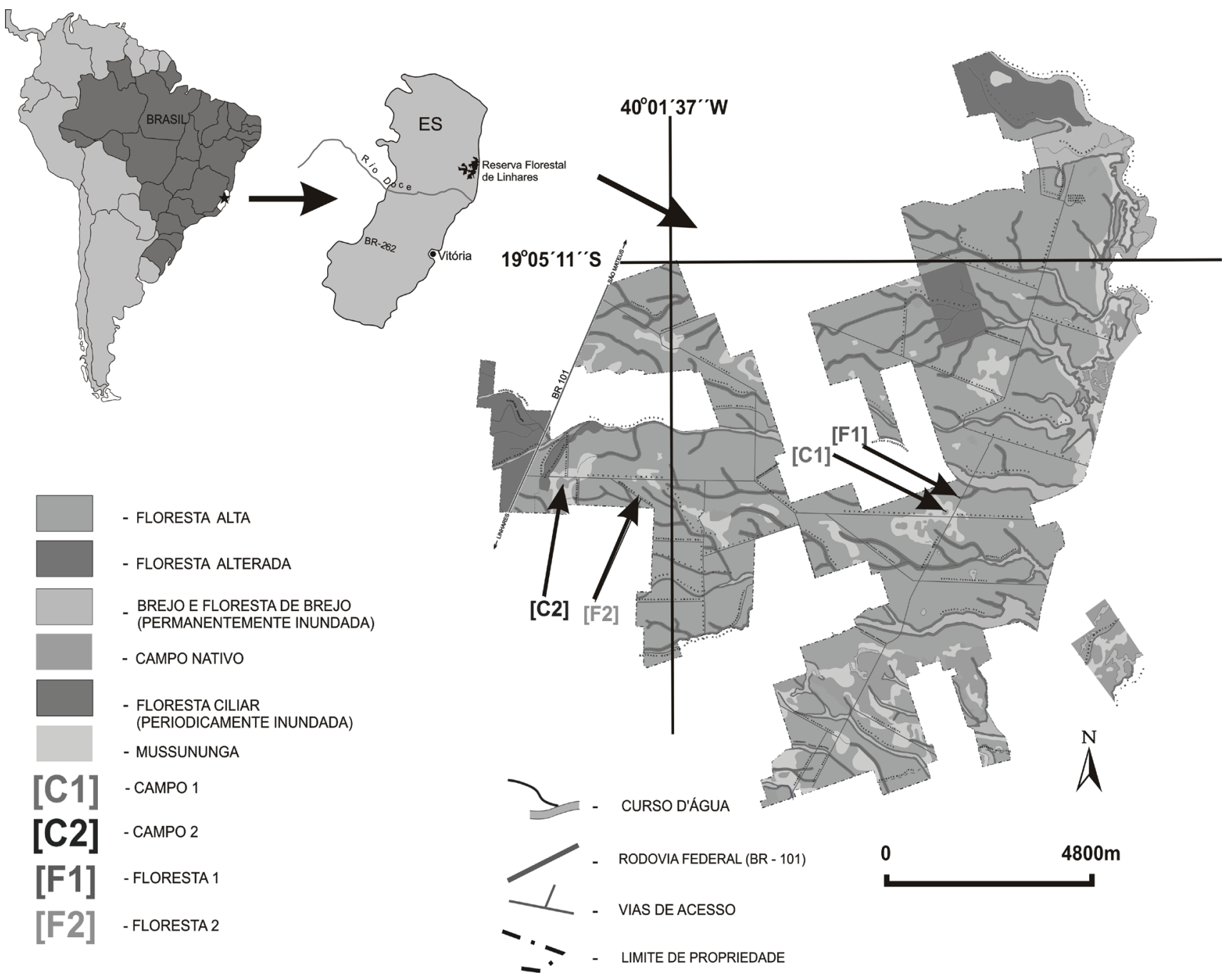

Figura 2. Localização da Reserva Natural da Companhia Vale do Rio Doce (RNVRD), localizada no município de Linhares, ES. A localização das áreas onde foram coletadas as duas amostras de campo (C) e de floresta (F) são indicadas pelas siglas C1, C2, F1 e F2. Figure 2. Location of the Vale do Rio Doce Natural Reserve (RNVRD), within the municipality of Linhares, ES. The sample location within the two areas containing forest $(\mathrm{F})$ and savanna $(\mathrm{C})$ are indicated by the $\mathrm{C} 1, \mathrm{C} 2, \mathrm{~F} 1$ and $\mathrm{F} 2$. 


\section{Material e métodos}

Trabalho de campo - Para realizar a análise de micropartículas carbonizadas preservadas em solos superficiais foram feitos, na superfície do solo, cortes de $15 \mathrm{~cm}$ de profundidade, $15 \mathrm{~cm}$ de comprimento e $15 \mathrm{~cm}$ de largura, em áreas de floresta e campo nas três áreas estudadas. Em cada corte foram coletadas amostras de cerca de $10 \mathrm{~cm}^{3} /$ cada, em três profundidades diferentes: uma na parte basal (15 $\mathrm{cm})$, uma na região intermediária $(7,5 \mathrm{~cm})$ e outra na superfície $(0 \mathrm{~cm})$. As características das áreas amostradas estão descritas nas tabelas 1,2 e 3 .

Método das micropartículas carbonizadas Segundo Tolonen (1986) a queima de material orgânico, tal como madeira, carvão produz numerosas micropartículas carbonizadas, que quando quantificadas em número de partículas por $\mathrm{cm}^{3}$ de solo ou sedimento, podem revelar a intensidade de paleoincêndios, tanto locais quanto regionais. A quantificação dessas micropartículas, quando combinada com registros palinológicos, permite a compreensão de sucessões vegetacionais, especialmente após impacto causado por incêndios. Para analisar as micropartículas carbonizadas utilizam-se lâminas preparadas pelo processo palinológico padrão (Cordeiro 1995, Ferraz-Vicentini 1999). Com base na morfologia de partículas de carvão preservadas em sedimentos e solos é possível distinguir os produtos da queima de combustível fóssil das partículas derivadas da queima de florestas (Tolonen 1986). Ao microscópio ótico, as micropartículas carbonizadas se apresentam como fragmentos totalmente pretos, opacos e angulosos, facilmente separados das estruturas resultantes da oxidação da matéria vegetal, que se apresentam mais claras e de cor marrom (Ferraz-Vicentini 1999).

Para a contagem de micropartículas carbonizadas, foi seguida a metodologia utilizada por Tolonen (1986), pela qual a quantificação é feita em três tamanhos distintos: $0-25 \mu \mathrm{m}, 26-50 \mu \mathrm{m}$ e $>51$ $\mu \mathrm{m}$. Segundo Tolonen (1986), as partículas maiores que $51 \mu \mathrm{m}$ são indicadoras de incêndios locais, pois são pesadas e dificilmente são transportadas a longas distâncias pelo vento, enquanto que partículas entre 26 e $50 \mu \mathrm{m}$ indicam incêndios regionais, pois são mais leves e podem ser transportadas a distâncias maiores. Já as partículas menores que $25 \mu \mathrm{m}$ indicam incêndios distantes. Como especificado pela metodologia de Stockmarr (1971) as micropartículas de carvão são analisadas nas lâminas palinológicas e contadas juntamente com os esporos de Lycopodium clavatum como mostra a figura 3 .

Até recentemente os únicos estudos realizados para calibração das categorias de tamanho de partículas carbonizadas contra eventos de incêndios conhecidos estavam restritos às regiões de alta latitude (Millspaugh \& Whitlock 1995, Enache \& Cumming 2006, Tinner et al. 2006). O primeiro estudo sobre a eficácia desta técnica em ambientes tropicais, através das previsões quantitativas da proximidade do incêndio, da área e da sua intensidade, foi realizado por Duffin et al. (2008), nas savanas do Sul da África e mostrou que a área fonte para micropartículas $>50 \mu \mathrm{m}$ situou-se entre 0 e $5 \mathrm{~km}$ e 10 a $15 \mathrm{~km}$ para micropartículas menores que $50 \mu \mathrm{m}$. Outra conclusão indicada pelos autores é que o acúmulo de micropartículas representa, em geral, uma somatória de vários episódios de incêndios.

Processamento químico das amostras de solo Os resíduos usados na contagem das micropartículas carbonizadas foram obtidos através da técnica palinológica, de acordo com o protocolo químico de amostras sedimentares proposto por Colinvaux et al. (1999). No laboratório, antes de iniciar o ataque químico, as amostras foram peneiradas com malha de $250 \mu \mathrm{m}$, para a remoção da fração areia grossa, e posteriormente lavadas com água destilada e decantadas por dois dias. Ao final de cada etapa do processamento químico, as amostras foram lavadas com água destilada e centrifugadas por 5 minutos, sendo descartado o excesso de água. Após a deposição dos sedimentos em béqueres, foram obtidas subamostras de $1 \mathrm{~cm}^{3}$ de cada amostra, que foram então tratadas quimicamente, segundo o protocolo resumido a seguir: adição de pastilhas de esporos exóticos de Lycopodium clavatum; destruição dos silicatos com HF (ácido fluorídrico); destruição dos fluorsilicatos com $\mathrm{HCl}$ a $10 \%$; acetólise com 9 partes de $\left(\mathrm{CH}_{3} \mathrm{CO}\right)_{2} \mathrm{O}$ (anidrido acético) e uma de $\mathrm{H}_{2} \mathrm{SO}_{4}$ (ácido sulfúrico).

Concentração de micropartículas carbonizadas - Os valores de concentração de micropartículas carbonizadas (número de partículas por centímetro cúbico) foram obtidos através do programa computacional Tilia (Grimm 1987) com a inserção dos seguintes parâmetros: volume da amostra de solo $\left(1 \mathrm{~cm}^{3}\right)$, número de esporos de Lycopodium clavatum presentes em cada pílula introduzida, número de pílulas utilizadas e número de micropartículas carbonizadas contadas durante a análise. Os resultados obtidos foram representados graficamente 

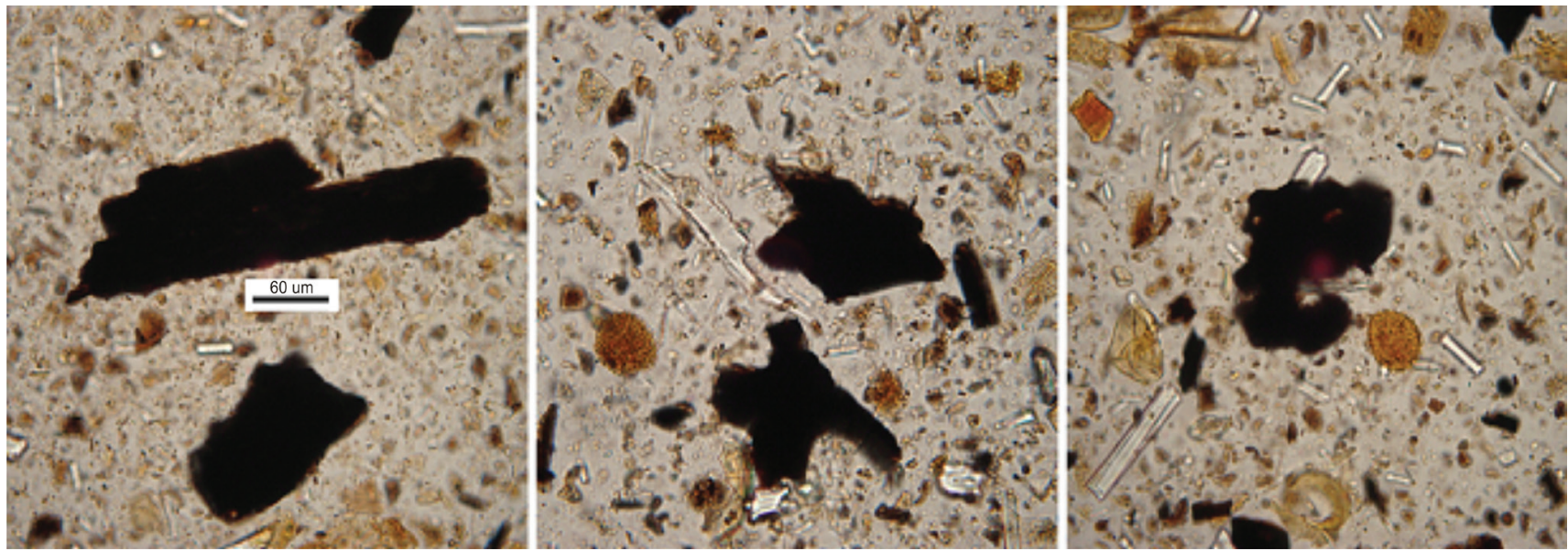

Figura 3. Fotomicrografias de partículas carbonizadas encontradas em solos superficiais do Núcleo Curucutu. A foto central e a da direita mostram um esporo exótico Lycopodium clavatum ao lado de partículas carbonizadas.

Figure 3. Photomicrographs of carbonized particles found in superficial soils of the Curucutu Nucleus. The photos at the center and right show the exotic spore of Lycopodium clavatum, next to carbonized particles.

através do programa Excel.

Aconcentração das micropartículas carbonizadas, realizadas pelo programa Tília é baseada na equação:

Concentração $=(\mathrm{EL} / \mathrm{EC}) \times \mathrm{PC} / \mathrm{vol}\left(\mathrm{cm}^{3}\right)$

Onde:

$\mathrm{EL}=$ número de esporos de Lycopodium clavatum, ou seja, o número de pastilhas empregadas $\times$ concentração de esporos (número de esporos em cada pastilha); $\mathrm{EC}=$ número contado de esporos de Lycopodium clavatum em cada amostra durante o procedimento de contagem de micropartículas; $\mathrm{PC}=$ número contado de partículas carbonizadas em cada amostra; vol $\left(\mathrm{cm}^{3}\right)$ é o volume de solo empregado na análise.

\section{Resultados e Discussão}

As figuras 4, 5 e 6 mostram a distribuição das concentrações de micropartículas carbonizadas encontradas nas amostras de solo superficial nas três profundidades $(0 \mathrm{~cm}, 7,5 \mathrm{~cm}$ e $15 \mathrm{~cm})$ em cada ponto, no Núcleo Curucutu, na Estrada de Ferro Sorocabana e na Reserva Florestal da Vale do Rio Doce, respectivamente. Os valores obtidos variaram entre 6.039 e 2.034 .374 micropartículas $/ \mathrm{cm}^{3}$ no Núcleo Curucutu, de 0 a 2.091.981 micropartículas/ $\mathrm{cm}^{3}$ na Estrada de Ferro Sorocabana e entre 2.322 e 17.623.188 micropartículas/ $\mathrm{cm}^{3}$ na RNVRD.

Curucutu e EFS - Nas amostras do Núcleo Curucutu (figura 4) observa-se que as partículas menores que $25 \mu \mathrm{m}$ encontram-se bem representadas em todas as amostras.

Dentro dessa categoria de tamanho, os dados mostram três padrões distintos de distribuição: (a) amostras com valores altos no presente (amostras coletadas a $0 \mathrm{~cm}$ ) e baixo no passado (amostras coletadas a $7,5 \mathrm{~cm}$ e $15 \mathrm{~cm}$ ); (b) baixo no presente e alto no passado; e (c) valores relativamente iguais nessas duas épocas. Na primeira categoria estão os pontos 2 (floresta), 4 (campo queimado), 6 (pinheiral) e 9 (campo). Na segunda categoria, ou seja, valores baixos no presente e altos no passado, estão os pontos 1 (pinheiral), 3 (floresta), 5 (campo), 7 (floresta), 8 (campo) e 10 (campo). Com valores relativamente parecidos, tanto nas amostras superficiais, como nas mais profundas, está o ponto 3 (floresta). A menor concentração de partículas $<25 \mu \mathrm{m}$ no Núcleo Curucutu foi encontrada no ponto 1 (pinheiral) na profundidade de $15 \mathrm{~cm}$.

Nas amostras da área da EFS as micropartículas carbonizadas $<25 \mu \mathrm{m}$, aparecem em todos os pontos, nos diferentes tipos de vegetação.

A menor concentração de micropartículas 
Tabela 1. Características geográficas das áreas amostradas no Núcleo Curucutu, Parque Estadual Serra do Mar.

Table 1. Geographical characteristics of the sampled areas within the Curucutu Nucleus of the Serra do Mar State Park.

\begin{tabular}{lllll}
\hline Pontos & Vegetação & Características do solo & Coordenadas & Altitude \\
\hline 1 & Pinheiral & Solo areno-argiloso & $23^{\circ} 59^{\prime} 24$ 'S $/ 46^{\circ} 44^{\prime} 27^{\prime \prime} \mathrm{W}$ & $774 \mathrm{~m}$ \\
2 & Floresta & Solo argiloso marrom claro & $23^{\circ} 59^{\prime} 38^{\prime \prime} \mathrm{S} / 46^{\circ} 44^{\prime} 30^{\prime \prime} \mathrm{W}$ & $855 \mathrm{~m}$ \\
3 & Floresta & Solo orgânico argiloso & $23^{\circ} 59^{\prime} 42^{\prime \prime} \mathrm{S} / 46^{\circ} 44^{\prime} 28^{\prime \prime} \mathrm{W}$ & $871 \mathrm{~m}$ \\
4 & Campo & solo argiloso amarelo claro. & $23^{\circ} 59^{\prime} 34^{\prime \prime} \mathrm{S} / 46^{\circ} 44^{\prime} 25^{\prime} \mathrm{W}$ & $812 \mathrm{~m}$ \\
5 & Queimado & Solo argiloso marrom claro. & $23^{\circ} 59^{\prime} 30^{\prime \prime} \mathrm{S} / 46^{\circ} 44^{\prime} 17^{\prime \prime} \mathrm{W}$ & $803 \mathrm{~m}$ \\
6 & Campo & Solo argiloso marrom & $23^{\circ} 59^{\prime} 22^{\prime \prime} \mathrm{S} / 46^{\circ} 44^{\prime} 21^{\prime \prime} \mathrm{W}$ & $794 \mathrm{~m}$ \\
7 & Pinheiral & Solo orgânico sobre solo arenoso úmido & $23^{\circ} 59^{\prime} 18^{\prime \prime} \mathrm{S} / 46^{\circ} 44^{\prime} 30^{\prime \prime} \mathrm{W}$ & $782 \mathrm{~m}$ \\
9 & Floresta & Solo argiloso marrom claro. & $23^{\circ} 59^{\prime} 09^{\prime} \mathrm{S} / 46^{\circ} 44^{\prime} 06^{\prime \prime} \mathrm{W}$ & $797 \mathrm{~m}$ \\
10 & Campo & Solo argiloso marrom claro tendendo a & $23^{\circ} 58^{\prime} 53^{\prime \prime} \mathrm{S} / 46^{\circ} 44^{\prime} 55^{\prime \prime} \mathrm{W}$ & $800 \mathrm{~m}$ \\
\hline
\end{tabular}

Tabela 2. Características geográficas das áreas amostradas na Estrada de Ferro Sorocabana.

Table 2. Geographical characteristics of the studied sites in the Sorocabana Railway region.

\begin{tabular}{|c|c|c|c|c|}
\hline Pontos & Vegetação & Características do solo & Coordenadas & Altitude \\
\hline 1 & $\begin{array}{l}\text { Regeneração } \\
\text { florestal }\end{array}$ & $\begin{array}{l}\text { Solo arenoso, serrapilheira com } \\
\text { muita matéria orgânica }\end{array}$ & $23^{\circ} 57^{\prime} 59^{\prime} \mathrm{S} / 46^{\circ} 38^{\prime} 55^{\prime \prime} \mathrm{W}$ & $709 \mathrm{~m}$ \\
\hline 2 & Floresta & Solo arenoso & $23^{\circ} 58^{\prime} 18^{\prime \prime} \mathrm{S} / 46^{\circ} 38^{\prime} 58^{\prime \prime} \mathrm{W}$ & $713 \mathrm{~m}$ \\
\hline 3 & Floresta & $\begin{array}{l}\text { Solo argilo-arenoso rico em } \\
\text { matéria orgânica }\end{array}$ & $23^{\circ} 58^{\prime} 43^{\prime} \mathrm{S} / 46^{\circ} 38^{\prime} 42^{\prime \prime} \mathrm{W}$ & $673 \mathrm{~m}$ \\
\hline 4 & Floresta & $\begin{array}{l}\text { Solo argiloso, areia com muita } \\
\text { matéria orgânica }\end{array}$ & $23^{\circ} 59^{\prime} 43^{\prime \prime} \mathrm{S} / 46^{\circ} 38^{\prime} 42^{\prime \prime} \mathrm{W}$ & $673 \mathrm{~m}$ \\
\hline 5 & Floresta & $\begin{array}{l}\text { Solo argiloso com muita matéria } \\
\text { orgânica }\end{array}$ & $23^{\circ} 58^{\prime} 48^{\prime} \mathrm{S} / 46^{\circ} 38^{\prime} 12^{\prime \prime} \mathrm{W}$ & $678 \mathrm{~m}$ \\
\hline 6 & Floresta & Solo argiloso amarelo & $23^{\circ} 58^{\prime} 49^{\prime \prime} \mathrm{S} / 46^{\circ} 38^{\prime} 12^{\prime \prime} \mathrm{W}$ & $670 \mathrm{~m}$ \\
\hline 7 & Campo & $\begin{array}{l}\text { Solo argiloso compactado, solo } \\
\text { avermelhado, arenoso e material } \\
\text { compactado argiloso com húmus }\end{array}$ & $23^{\circ} 58^{\prime} 57^{\prime \prime} \mathrm{S} / 46^{\circ} 38^{\prime} 13^{\prime \prime} \mathrm{W}$ & $698 \mathrm{~m}$ \\
\hline 8 & Campo & Solo argiloso compactado & $23^{\circ} 58^{\prime} 59^{\prime} \mathrm{S} / 46^{\circ} 38^{\prime} 15^{\prime \prime} \mathrm{W}$ & $677 \mathrm{~m}$ \\
\hline 9 & Campo/Floresta & Solo arenoso & $23^{\circ} 58^{\prime} 59^{\prime} \mathrm{S} / 46^{\circ} 38^{\prime} 16^{\prime \prime} \mathrm{W}$ & $693 \mathrm{~m}$ \\
\hline 10 & Campo & $\begin{array}{l}\text { Solo arenoso com argila e muita } \\
\text { matéria orgânica na serrapilheira }\end{array}$ & $23^{\circ} 58^{\prime} 57^{\prime \prime} \mathrm{S} / 46^{\circ} 38^{\prime} 12^{\prime \prime} \mathrm{W}$ & $687 \mathrm{~m}$ \\
\hline
\end{tabular}




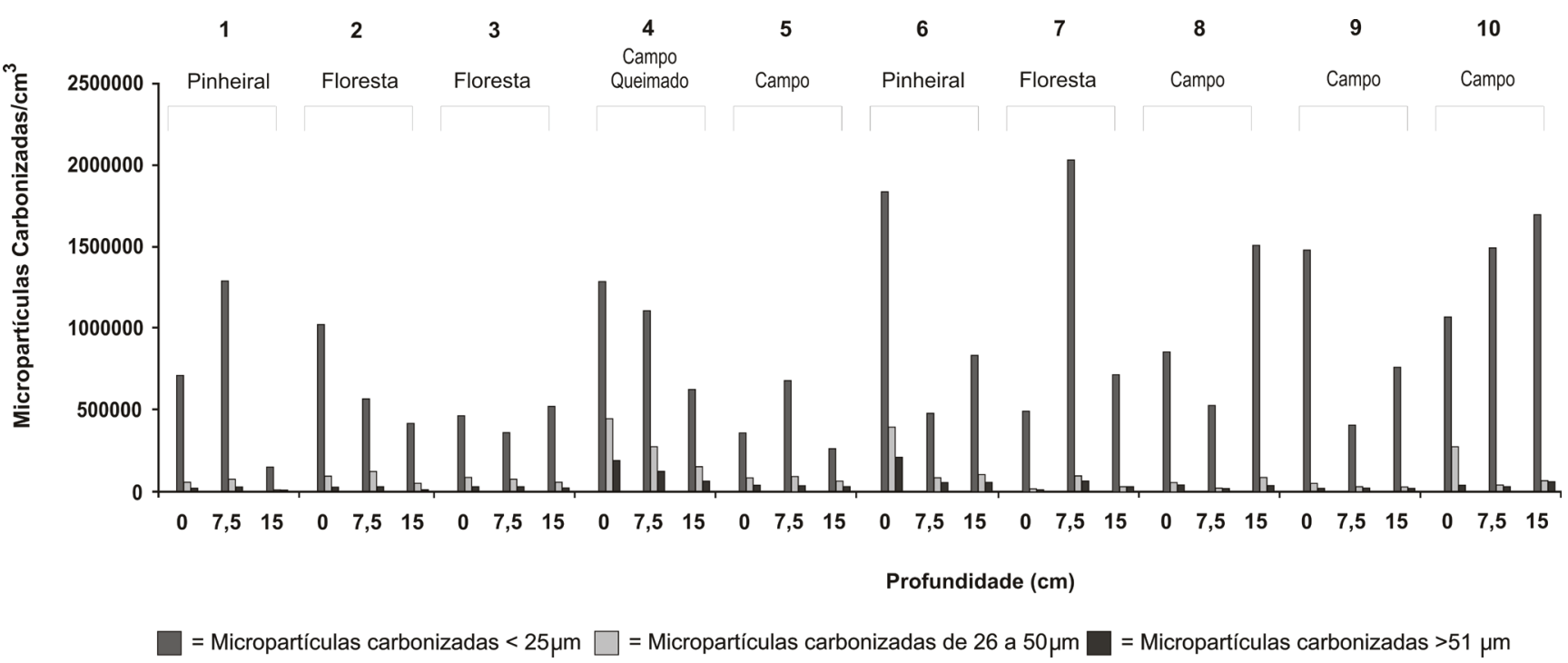

Figura 4. Concentração total de micropartículas carbonizadas nos dez pontos amostrais no Núcleo Curucutu. Em cada ponto observam-se os valores referentes às três categorias de tamanhos das partículas.

Figure 4. Total concentration of carbonized microparticles in the ten sampled points of the Curucutu Nucleus. In each point, the values belonging to the three size categories of the particles are given.

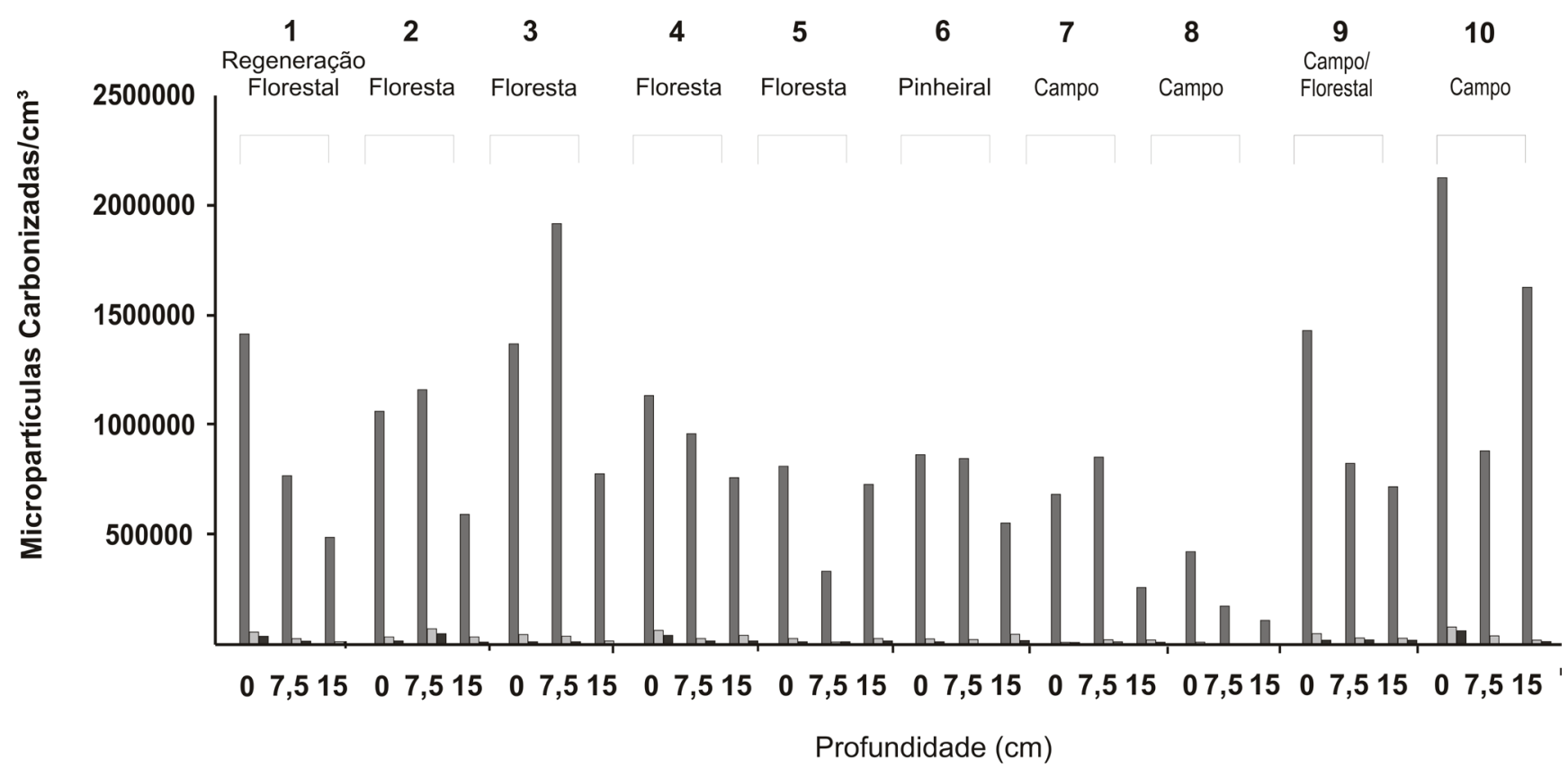

Micropartículas carbonizadas $<25 \mu \mathrm{m} \quad \square$ Micropartículas carbonizadas de 26 a $50 \mu \mathrm{m}$

Micropartículas Carbonizadas $>51 \mu \mathrm{m}$

Figura 5. Concentração total de micropartículas carbonizadas nos dez pontos amostrais da área próxima à Estrada de Ferro Sorocabana. Figure 5. Total concentration of microparticles in the ten samples within the area next to the Sorocabana Railway. 


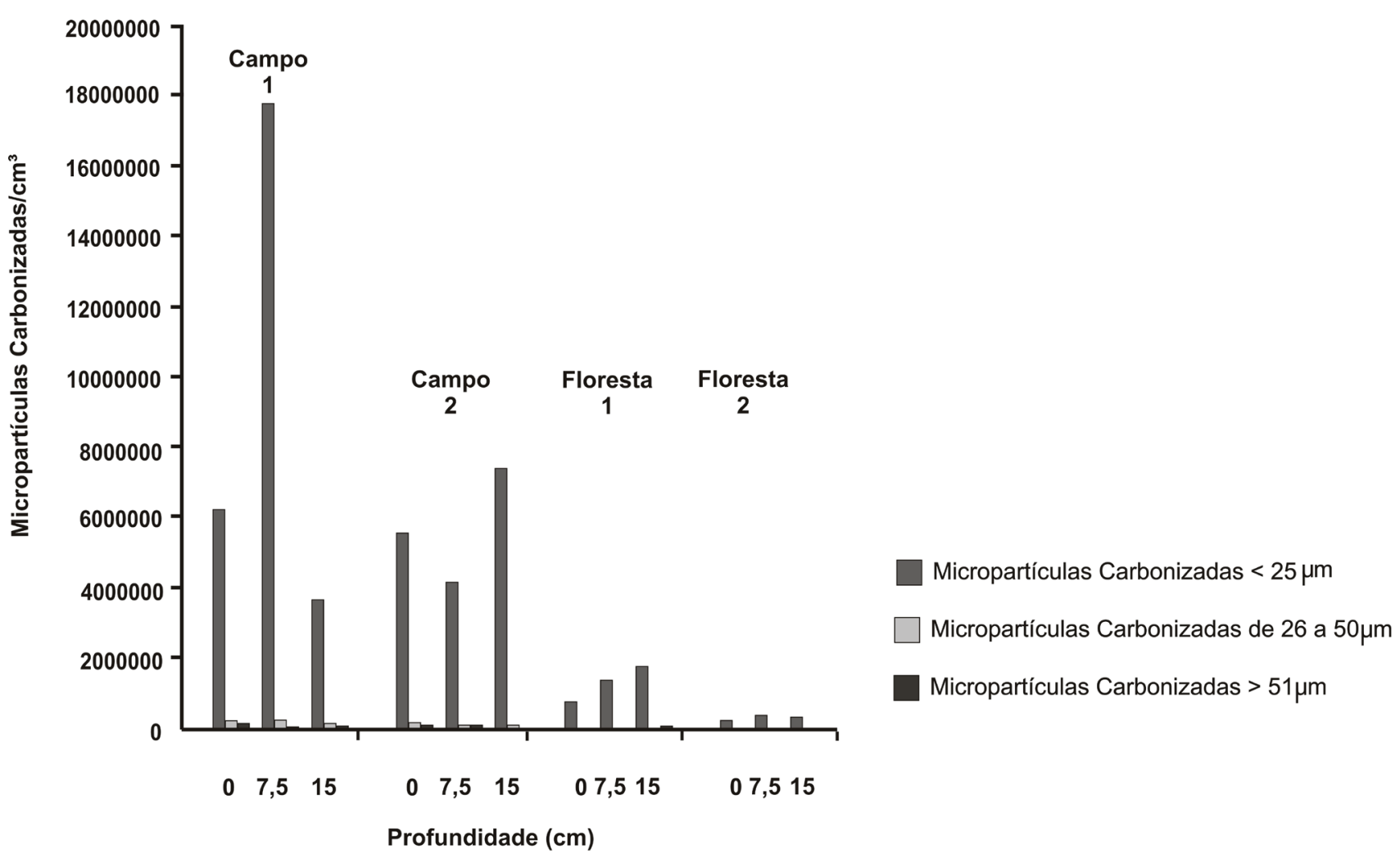

Figura 6. Concentração total de micropartículas carbonizadas nos quatro pontos amostrados na Reserva Natural do Vale do Rio Doce. Figure 6. Total concentration of carbonized microparticles in the four samples of the Vale do Rio Doce Natural Reserve.

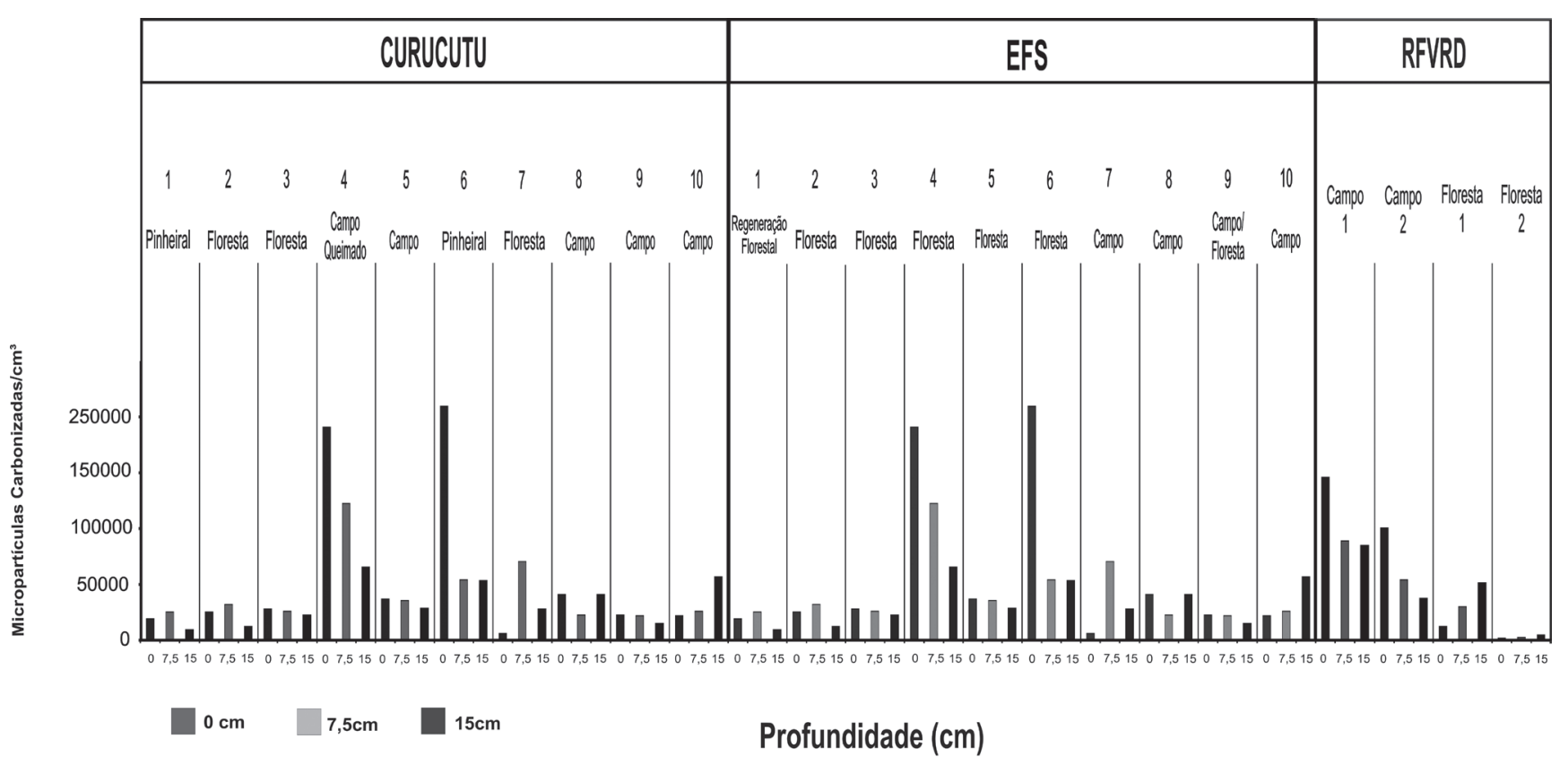

Figura 7. Distribuição e concentração de micropartículas carbonizadas maiores que $50 \mu \mathrm{m}$, indicadoras de incêndios locais, em todas as amostras estudadas.

Figure 7. Distribution and concentration of carbonized microparticles larger than $50 \mu \mathrm{m}$, indicative of local fires, in all samples. 
Tabela 3. Características geográficas das áreas amostradas na RNVRD.

Table 3. Geographical characteristics of the sampled areas within the RNVRD.

\begin{tabular}{llll}
\hline Pontos & Vegetação & Características do solo & Coordenadas \\
\hline C1 & Campo & Solo arenoso com pouca matéria orgânica & $19^{\circ} 12^{\prime} 680^{\prime} \mathrm{S} / 39^{\circ} 57^{\prime} 84^{\prime \prime} \mathrm{W}$ \\
C2 & Floresta & $\begin{array}{l}\text { Solo bastante arenoso com pouca matéria } \\
\text { orgânica }\end{array}$ & $19^{\circ} 09^{\prime} 197^{\prime} \mathrm{S} / 40^{\circ} 03$ '94” W \\
F1 & Floresta & Solo argilo-arenoso vermelho com pouca areia & $19^{\circ} 12^{\prime} 33^{\prime} \mathrm{S} / 39^{\circ} 57^{\prime} 633^{\prime} \mathrm{W}$ \\
F2 & Floresta & Solo argilo-arenoso vermelho & $19^{\circ} 09^{\prime} 20^{\prime} \mathrm{S} / 40^{\circ} 02^{\prime} 75^{\prime \prime} \mathrm{W}$ \\
\hline
\end{tabular}

carbonizadas de todas as classes de tamanho aparece no ponto 8 (campo), na profundidade $15 \mathrm{~cm}$. A maior concentração de micropartículas carbonizadas $<25$ $\mu \mathrm{m}$, de $26-50 \mu \mathrm{m}$ e $>51 \mu \mathrm{m}$ aparecem no ponto 10 (campo) na amostra superficial $(0 \mathrm{~cm})$.

RNVRD - A representação dos valores de micropartículas nos quatro pontos da Reserva Natural da Vale do Rio Doce é mostrada na figura 6.

Nas amostras da RNVRD há uma clara separação no padrão de deposição de partículas carbonizadas entre as amostras de campo (C1 e $\mathrm{C} 2)$ e floresta (F1 e F2). A amostra campo 1 é a que apresentou o maior número de partículas $<25 \mu \mathrm{m}$, ou seja, ca. 1.800 .000 partículas $/ \mathrm{cm}^{3}$. Nota-se também nessa área a ausência de partículas carbonizadas maiores que $25 \mu \mathrm{m}$ nas amostras de solo superficial da Floresta 1 e Floresta 2.

Comparando-se os valores dessas micropartículas, precipitadas nos pontos de campo com maior valor de micropartículas $<25 \mu \mathrm{m}$ nas duas regiões estudadas, percebe-se que os valores do campo 1 da RNVRD estão numa ordem de magnitude até 10 vezes maior do que na amostra 10 do Núcleo Curucutu.

Partículas > $>51 \mu \mathrm{m}$ - A distribuição de micropartículas carbonizadas maiores que $51 \mu \mathrm{m}$, usadas neste estudo como indicadores de incêndios locais, exibida na figura 7, para as três áreas estudadas, mostra que a maior concentração dessas partículas, de uma forma geral, ocorre nas amostras de campos das três localidades estudadas, como por exemplo, os pontos 4 (campo queimado) e no ponto 6 (pinheiral) do Núcleo Curucutu que provavelmente foi submetido a incêndios antes do plantio desses táxons exóticos. Na EFS, contudo, a maior concentração de micropartículas maiores que $51 \mu \mathrm{m}$ ocorreu nos pontos 4 e 6 , hoje cobertos por floresta. Na RNVRD, essas micropartículas estão praticamente restritas aos pontos de campo $\mathrm{C} 1$ e $\mathrm{C} 2$.

Apesar dos valores relativamente baixos de micropartículas maiores $51 \mu \mathrm{m}$ nos solos superficiais das áreas de florestas do Núcleo Curucutu, selecionadas para este estudo, os dados sugerem que as mesmas já foram impactadas pelo fogo, muito provavelmente causado pelo uso e ocupação da Fazenda Curucutu, que explorou carvão através da queima da vegetação nativa, antes da implantação do Parque Estadual. Evidência para essa conclusão encontra-se nos vários fornos encontrados em áreas de mata e que estão espalhados pela Reserva. Da mesma forma, suas áreas de campo também sofreram recentemente com incêndios como verificado no ponto 4 (campo queimado) onde foram encontrados restos de um grande balão de festas juninas. Por outro lado, o solo superficial do ponto 6 (pinheiral), possui uma concentração levemente maior que a do campo queimado, o que pode ser explicado pelo tipo de atividade comercial na área antes da formação do Parque Estadual. Como é de esperar que a queima de biomassa florestal gere maior quantidade de micropartículas carbonizadas que a de biomassa campestre, supõe-se que as maiores concentrações encontradas nos campos sejam explicadas por uma somatória maior de episódios de incêndios nesses ecossistemas como sugerido pela avaliação do método de micropartículas carbonizadas feita por Duffin et al. (2008).

Por outro lado, o padrão de deposição de micropartículas nos campos dos pontos 8,9 e 10 do Núcleo Curucutu, mostra que, com exceção do ponto 10, não houve uma significativa intensidade de queima no passado recente, uma vez que os valores de partículas maiores que $51 \mu \mathrm{m}$ são relativamente inferiores aos encontrados nos campos da RNVRD, que aparentemente sofrem ainda com incêndios. Essa constatação não é surpreendente, uma vez que o 
acesso a essas duas áreas é muito diferente. Enquanto no Núcleo Curucutu o acesso só é possível através de pedidos formais ao Instituto Florestal do Estado de São Paulo, os campos da RNVRD podem ser facilmente acessados através de rodovias estaduais sem o consentimento prévio da empresa Vale do Rio Doce.

Observa-se assim, nesta primeira análise preliminar, que o impacto antrópico através da queima da vegetação no Núcleo Curucutu e na EFS foi pontual no passado recente e que de forma geral, não há evidência, baseada nas micropartículas de carvão, indicadora de incêndios locais de e que o tipo de vegetação nessas áreas tenha sido controlado primordialmente por um diferencial na freqüência de incêndios locais.

Sucessão ecológica - Os pontos de floresta 1, 2, 3 e 5 da região da antiga Estrada de Ferro Sorocabana (EFS) também mostram baixas concentrações de micropartículas $>51 \mu \mathrm{m}$, o que sugere uma menor taxa de episódios de incêndios. Por outro lado, os pontos 4 e 6 apresentaram valores de concentração parecidos com o do ponto 4 (campo queimado do Núcleo Curucutu), o que sugere a ocorrência de grandes incêndios em sua história recente. Esses dados são importantes, pois mostram que a alta frequência de queimadas não conseguiu alterar ou impedir a cobertura da área por vegetação de floresta, provavelmente devido às altas taxas de precipitação reinantes nessa região.

As áreas de campo da antiga EFS, assim como a maioria dos campos analisados do Curucutu, mostram-se com menor taxa de incêndios do que as florestas dos pontos 4 e 6 . Esses valores são parecidos com os de campo e floresta do Curucutu. Os resultados para a RNVRD mostram que as duas áreas de florestas escolhidas para o estudo sofreram pouco com incêndios no passado recente, pois seus valores são praticamente similares aos das florestas 1,2 e 3 do Curucutu, e 1, 2 e 3 da antiga EFS. Contudo, os campos da RNVRD possuem valores mais altos dos que os campos 8, 9 e 10 do Curucutu e dos campos 7, 8 e 9 da antiga EFS. Esses resultados sugerem que os campos da RNVRD sofrem com a queima, num grau de intensidade maior do que os campos da Serra do Mar de São Paulo, com exceção do campo 4 (queima por balão). Esta interpretação é apoiada em relatos dos botânicos e mateiros que trabalham na RNVRD que afirmam que essa vegetação sofre queima frequente nos meses secos. Aliado a esse fato, está o fácil acesso à área através da Rodovia BR 101 e a topografia local favorável à ação antrópica.
Este estudo mostra que as florestas tropicais da região da Mata Atlântica, apesar de sua localização em uma das áreas mais úmidas do Brasil, onde a precipitação anual média é superior a $1.500 \mathrm{~mm}$, sofrem esporadicamente com incêndios. Segundo Hammond et al. (2006) florestas úmidas sofrem frequentemente com incêndios nas Guianas, devido a impactos antrópicos. Carcaillet et al. (2002) relatam que nos últimos 2.000 anos, na Amazônia, incêndios também estão presentes no registro paleoambiental igualmente associados à influência antrópica. A ocorrência atual de incêndios florestais antropogênicos em locais hiperúmidos da Amazônia, observada em florestas por Nelson \& Irmão (1998), sugere que sem a presença humana, dificilmente as regiões florestadas seriam queimadas naturalmente. Em seus estudos de paleoincêndios na região Sudeste do Brasil, Pessenda et al. (2004) mostram que a região do Curucutu sofre com a influência antrópica há pelo menos 9.000 anos.

Implicações paleoambientais para o Núcleo Curucutu - Quando se compara a concentração de micropartículas de carvão nos sedimentos turfosos holocênicos estudados por Medeiros (2006) no Núcleo Curucutu, percebe-se que os valores encontrados por essa autora em suas análises palinológicas são irrisórios quando comparados com a precipitação moderna de micropartículas carbonizadas, das três categorias de tamanho, nos solos superficiais atuais. Se aplicarmos os resultados aqui apresentados à interpretação paleoambiental do Núcleo Curucutu de Medeiros (2006), pode-se afirmar que durante os últimos 28.000 anos sua cobertura vegetal foi pouco impactada pelo fogo. Esta conclusão também é apoiada pelos dados de Mofatto (2005) e Pessenda et al. (2009), que em análises baseadas em isótopos de carbono, concluíram que o período cronológico equivalente ao Último Máximo Glacial, no hemisfério norte, foi bastante úmido nessa região. Desta forma, mesmo com o grande recuo da linha de costa nesse setor do atual território do Estado de São Paulo, impulsionado pela redução do nível do mar durante a última glaciação, altos índices de umidade, oriunda do Oceano Atlântico e/ou da intensificação das massas de ar de origem polar, continuaram a penetrar nessa região, como foi sugerido por De Oliveira (1992).

Os resultados aqui apresentados não sugerem que a frequência de incêndios recentes, ou seja, os que ocorreram provavelmente nos últimos 60 anos, seja um fator importante para explicar da existência 
do ecótono floresta/campo na área atual da Floresta Atlântica. Por outro lado, os dados de micropartículas de carvão, encontrados em solos superficiais do Núcleo Curucutu e da área próxima à Estrada de Ferro Sorocabana, estão em sintonia com as conclusões paleoambientais de Garcia (2003), Medeiros (2006), Mofatto (2005) e Pessenda et al. (2009) para a área amostrada na Serra do Mar, em São Paulo, ou seja, de que os campos dessa região são naturais e não antrópicos. Medeiros (2006), Mofatto (2005) e Pessenda et al. (2009) mostram conclusivamente que os atuais campos desse setor da Serra do Mar podem ser denominados de "paleocampos", que foram estabelecidos antes até do que o máximo da última glaciação do Pleistoceno, ou seja, por volta de 18.000 anos AP (idade não calibrada).

Embora o fogo não seja, provavelmente, o fator principal e determinante da fisionomia vegetal das localidades estudadas, ele pode contribuir com o processo de sucessão vegetal e retardar a regeneração das florestas. Contudo, em relação às hipóteses escolhidas para este estudo, pode-se afirmar que não há evidência suficiente de impactos antrópicos nas três áreas escolhidas para justificar a presença de campos nessas áreas do domínio da Mata Atlântica.

Há evidência de que, em tempos recentes, o fogo teve amplo impacto, principalmente na Reserva Natural da Companhia Vale do Rio Doce e bem menor do que nas duas áreas estudadas em São Paulo, de onde se pode concluir que há maior proteção nessas duas áreas contra o efeito deletério antrópico, possivelmente devido a um maior controle no acesso de visitantes

\section{Agradecimentos}

Os autores agradecem ao Dr. Luiz Carlos Ruiz Pessenda, do Laboratório de Carbono 14, do CENA/USP e Dr. Kenitiro Suguio, Universidade Guarulhos e IG/USP, pelas sugestões e apoio durante o desenvolvimento desta pesquisa, aos avaliadores anônimos pelas criteriosas sugestões. Agradecemos ao Instituto Florestal-IF de São Paulo que permitiu o trabalho no Núcleo Curucutu, Parque Serra do Mar e aos funcionários do parque que ajudaram os pesquisadores durante os trabalhos de campo. Aos funcionários e pesquisadores da Reserva Natural Vale do Rio Doce pelo apoio durante os trabalhos de campo. Agradecemos também a Marco Felipe Raczka e Álvaro Buso, pela coleta das amostras da Reserva Natural Vale do Rio Doce.

\section{Literatura citada}

Ab'Saber, A.N. 1971. A organização natural das paisagens inter e subtropicais brasileiras. In: M.G Ferri (coord.). III Simpósio sobre o Cerrado. Edgard Blücher, São Paulo, pp. 1-14.

Carcaillet, C. 2002. Holocene biomass burning and global dynamics of the carbon cycle. Chemosphere 49: 845-863.

Colinvaux, P.A., De Oliveira, P.E. \& Patiño, J.E.M. 1999. Amazon Pollen Manual and Atlas. Harwood Academic Publishers, New York.

Cordeiro, R.C. 1995. Mudanças paleoambientais e ocorrência de incêndios nos últimos 7400 anos, na região de Carajás, Pará. Dissertação de Mestrado, Universidade Federal Fluminense, Niterói.

Christofoletti, A. 1966. Considerações a propósito da geografia física dos cerrados. Noticia Geomorfológica 11: 5-32.

De Oliveira, P.E. 1992. A Palynological record ol late Quaternary vegetacion and climatic change in southeastern Brazil. Tese de Doutorado, Ohio State University, Columbus.

Duffin, K.I., Gilson, L. \& Willis, K.J. 2008. Testing the sensitivity of charcoal as an indicator of fire events in savana environments: quantitative predictions of fire proximity, area and intensity. The Holocene 18: 279-291.

Eiten, G. 1994. Vegetação do Cerrado. In: M. Novais Pinto (coord.). Cerrado: Caracterização, ocupação e perspectivas. 2 ed. Ed. UnB/ SEMATEC, Brasília, pp. 17-74.

Enache, M.D. \& Cuming, B.F. 2006.Tracking recorded fires using charcoal morphology from the sedimentary sequence of Prosser Lacke, British Columbia (Canada). Quaternary Research 65: 282-292.

Ferraz-Vicentini, K.R. 1999. História do fogo no cerrado - Uma análise palinológica. Tese de Doutorado, Universidade de Brasília, Brasília.

Garay, I. \& Rizzini, C.M. 2004. A Floresta Atlântica de Tabuleiros. 2 ed. Vozes, Petrópolis.

Garcia, R.J.F. 2003. Estudo florístico dos campos alto-montanhosos e matas nebulares do Parque Estadual da Serra do Mar, Núcleo Curucutu, São Paulo, SP. Brasil. Tese de Doutorado, Universidade de São Paulo, São Paulo.

Goodland, R. 1979. Ecologia do Cerrado. EDUSP, São Paulo.

Grimm, E.C. 1987. CONISS: a Fortran 77 program 
for stratigraphically constrained cluster analysis by the method of incremental sum of squares. Computers \& Geosciences 13: 13-35.

Hammond,D.S.,Steege,H.\&Van DerBorg,K.2006. Upland soil charcoal in the wet Tropical Forests of Central Guyana. Biotropica 39: 153-160.

Medeiros, V.B. 2006. Origem dos campos de altitude da Serra do Mar: uma investigação paleoambiental no Parque Estadual da Serra do Mar, Núcleo Curucutu, São Paulo, Brasil. Monografia de Bacharelado em Ciências Biológicas, Universidade Guarulhos, Guarulhos.

Millspaugh, S.H. \& Whitlock, C. 1995. A 750-years fire history based on lake sediment records in central Yellowstone National Park, USA. The Holocene 5: 92-283.

Mofatto, M. 2005. Estudo multi/interdisciplinar de reconstrução da vegetação e clima do Parque Estadual da Serra do Mar - Núcleo Curucutu, São Paulo, SP, no Quaternário tardio. Dissertação de Mestrado, Centro de Energia Nuclear na Agricultura/Universidade de São Paulo, Piracicaba.

Nelson, B.W \& Irmão, M.N. 1998. Fire penetration in standing Amazon forests. In: Anais do Simpósio Brasileiro de Sensoriamento Remoto, Santos, pp. 1471-1482.

Nogueira, S.M.B. 2002. Análise da sustentabilidade ambiental e diretrizes para o zoneamento do Núcleo Curucutu do Parque Estadual da Serra do Mar (SP). Dissertação de Mestrado, Universidade Estadual Paulista, Rio Claro.

Pessenda, L.C.R., Gouveia, S.E.M., Aravena, R., Boulet, R. \& Valencia, E.P.E. 2004. Holocene fire and vegetation changes southeastern Brazil as deduced from fossil charcoal and soil carbon isotopes. Quaternary International 114: 35-43.

Pessenda, L.C.R., De Oliveira, P.E., Mofatto, M., Medeiros, V.B., Garcia, R.J.F., Aravena, R., Bendassoli, J.A., Leite, A.Z., Saad, A.R. \& Etchebehere, M.L. 2009. The evolution of a tropical rainforest/grassland mosaic in southeastern Brazil since 28,000 yr BP based on carbon isotopes and pollen records. Quaternary Research 71: 437-452.

Pillar, V.P. 2003. Dinâmica da expansão florestal em mosaico de floresta e campo no Sul do Brasil. In: V. Claudino-Sales (ed.). Ecossistemas brasileiros: manejo e conservação. Expressão Gráfica Editora, Fortaleza, pp. 209-216.

Radambrasil. 1983. Folhas SE 24 - Espírito Santo/ Rio Doce. Levantamento dos Recursos Naturais, vol. 34. Ministério de Minas e Energia/IBGE, Rio de Janeiro.

Rawitscher, F. K. 1944. Problemas de fitoecologia com considerações especiais sobre o Brasil Meridional. Boletim da Faculdade de Filosofia Ciências e Letras da USP, Botânica, 41: 5-153.

Rizzini, C.M., Aduan, R.E., Jesus, R. \& Garay, I. 1997. Floresta pluvial de tabuleiros, Linhares, ES, Brasil: Sistemas primários e secundários. Leandra 12: 54-76.

Sant'anna Neto, J.L. 1990. Ritmo climático e a gênese das chuvas na zona costeira paulista. São Paulo. SP. Brasil. São Paulo. Dissertação de Mestrado, Universidade de São Paulo, São Paulo.

Stockmarr, J. 1971. Tablets with spores used in absolute pollen analysis. Pollen et Spores 13: 615-621.

Tinner, W., Hofstetter, S., Zeugin, F., Conedera, M., Wohlgemuth, T., Zimmermann, L. \& Zweifel, R. 2006. Long-distance transport of macroscopic charcoal by an intensive crown fire in the Swiss Alps - implication for fire history reconstruction. The Holocene 16: 192-287.

Tolonen, K. 1986. Charred particules analyses. In: B. E. Berglund (coord.). Handbook of Holocene Palaeoecology and Palaeohydrology. John Wiley \& Sons, New York. pp. 485-490.

Warming, E. 1908. Lagoa Santa. Contribuição para a Geographia Phytobiologica. (trad. A. Loefgren). Imprensa Official do Estado de Minas Gerais, Belo Horizonte. 